\title{
Benchmarks for multicomponent diffusion and electrochemical migration
}

\author{
Rasouli, Pejman; Steefel, Carl I.; Mayer, K. Ulrich; Rolle, Massimo
}

Published in:

Computational Geosciences

Link to article, DOI:

10.1007/s10596-015-9481-z

Publication date:

2015

Document Version

Peer reviewed version

Link back to DTU Orbit

Citation (APA):

Rasouli, P., Steefel, C. I., Mayer, K. U., \& Rolle, M. (2015). Benchmarks for multicomponent diffusion and electrochemical migration. Computational Geosciences, 19(3), 523-533. https://doi.org/10.1007/s10596-015$9481-z$

\section{General rights}

Copyright and moral rights for the publications made accessible in the public portal are retained by the authors and/or other copyright owners and it is a condition of accessing publications that users recognise and abide by the legal requirements associated with these rights.

- Users may download and print one copy of any publication from the public portal for the purpose of private study or research.

- You may not further distribute the material or use it for any profit-making activity or commercial gain

- You may freely distribute the URL identifying the publication in the public portal

If you believe that this document breaches copyright please contact us providing details, and we will remove access to the work immediately and investigate your claim 
This is a Post Print of the article published on line $1^{\text {st }}$ May 2015 and printed June 2015 in Computational Geosciences, 19, 523-533. The publishers' version is available at the permanent link: doi:10.1007/s10596-015-9481-z

\title{
Benchmarks for multicomponent diffusion and electrochemical migration
}

\author{
Pejman Rasouli $^{1^{*}}$, Carl I. Steefel ${ }^{2}$, K. Ulrich Mayer ${ }^{1}$ and Massimo Rolle ${ }^{3}$ \\ ${ }^{1}$ Department of Earth, Ocean and Atmospheric Sciences, University of British Columbia, 2207 \\ Main Mall, Vancouver, BC V6T 1Z4, Canada \\ ${ }^{2}$ Earth Sciences Division, Lawrence Berkeley National Laboratory, Berkeley, CA 94720, USA \\ ${ }^{3}$ Department of Environmental Engineering, Technical University of Denmark, Miljøvej \\ Building 115, 2800 Kgs. Lyngby, Denmark \\ *corresponding author: prasouli@eos.ubc.ca
}




\section{Abstract}

2 In multicomponent electrolyte solutions, the tendency of ions to diffuse at different rates results

3 in a charge imbalance that is counteracted by the electrostatic coupling between charged species

4 leading to a process called "electrochemical migration" or "electromigration". Although not

5 commonly considered in solute transport problems, electromigration can strongly affect mass

6 transport processes. The number of reactive transport models that consider electromigration has

7 been growing in recent years, but a direct model inter-comparison that specifically focuses on the

8 role of electromigration has not been published to date. This contribution provides a set of three

9 benchmark problems that demonstrates the effect of electric coupling during multicomponent

10 diffusion and electrochemical migration and at the same time facilitates the inter-comparison of

11 solutions from existing reactive transport codes. The first benchmark (Lichtner, 1995) focuses on

12 the 1D-transient diffusion of $\mathrm{HNO}_{3}(\mathrm{pH}=4)$ in a $\mathrm{NaCl}$ solution into a fixed concentration

13 reservoir, also containing $\mathrm{NaCl}$ - but with lower $\mathrm{HNO}_{3}$ concentrations $(\mathrm{pH}=6)$. The second

14 benchmark describes the $1 \mathrm{D}$ steady-state migration of the sodium isotope ${ }^{22} \mathrm{Na}$ triggered by

15 sodium chloride diffusion in neutral $\mathrm{pH}$ water. The third benchmark (Rolle et al., 2013) presents

16 a flow-through problem in which transverse dispersion is significantly affected by

17 electromigration. The system is described by $1 \mathrm{D}$ transient and 2D steady-state models. Very

18 good agreement on all of the benchmarks was obtained with the three reactive transport codes

19 used: CrunchFlow, MIN3P and PHREEQC.

21 Keywords: Reactive transport modeling, multicomponent diffusion, electromigration, model

22 intercomparison, benchmark 


\section{1. Introduction}

24 It is well known that diffusive transport in multicomponent electrolyte systems cannot be fully

25 described by Fickian diffusion alone, but is affected by a variety of processes including the

26 electrostatic interactions between individual ions (Vinograd and McBain, 1941; Newman, 1973;

27 Ben-Yaakov, 1981; Cussler, 1997). Each dissolved species is subject to its own species-

28 dependent diffusion coefficient, affected by parameters such as charge and size of the ion

29 (Cussler, 1997) and ionic conductivity (Lasaga, 1979). As a result, dissolved species will tend to

30 diffuse at different rates, promoting the development of a charge imbalance in solution.

31 However, positively and negatively charged species are also affected by electric coupling, which

32 ensures that charge balance in solution is maintained. Generally speaking, "large" cations and

33 "small" anions are tied together electrostatically (Newman, 1973; Cussler, 1997) to enforce

34 electroneutrality at the macroscale - an essential condition in electrolyte solutions (Lichtner,

35 1996; Van Cappellen and Gaillard, 1996). This electric coupling leads to an additional mass

36 transport process called "electrochemical migration" or "electromigration" (Newman, 1991;

37 Ben-Yaakov, 1981). Fick's law neglects these interactions, describes ion migration solely based

38 on concentration gradients, and consequently does not consider the electric field generated by

39 electrostatic bonding (coulombic interactions) of charged species (Lasaga, 1979; McDuff and

40 Ellis, 1979; Newman, 1991; Lichtner, 1996; Van Cappellen and Gaillard, 1996). In a

41 multicomponent system that includes charged species, diffusive ion migration is therefore better

42 described by the Nernst-Plank equation, a formulation that explicitly considers the electric

43 coupling between species and ensures the conservation of charge (Lasaga, 1979; McDuff and

44 Ellis, 1979; Newman, 1991; Lichtner, 1996; Van Cappellen and Gaillard, 1996; Boudreau et al.,

45 2004; Liu et al., 2011; Steefel et al., 2014). 
In some cases, electrostatic interactions between diffusing species can have a strong

47 effect on ion mobility and can produce unexpected behavior such as uphill diffusion (e.g.:

48 Oelkers, 1996). In addition, apparent diffusion coefficients (i.e. diffusion coefficients derived

49 from Fick's law) may show a strong dependency on concentrations. Considering that the

50 quantification of diffusion coefficients is labor-intensive (Tyrell, 1961; Cussler, 1997), it is

51 impractical to determine apparent diffusion coefficients as a function of solution composition for

52 a range of conditions. Instead, it is advantageous to consider electrochemical interactions

53 affecting diffusion explicitly rather than lumping this effect into empirically measured apparent

54 diffusion coefficients.

55 Reactive transport models are commonly used for the quantitative investigation of flow,

56 transport and reaction processes in porous media. These models aid with the verification of

57 conceptual models, are used to design and evaluate experiments, and assist with the

58 interpretation of field data in the fields of geology, engineering and environmental research

59 (Boudreau, 1997; Kang et al. , 2006; Steefel et al., 2003; Wang and Van Cappellen, 1996;

60 MacQuarrie and Mayer 2005). Traditionally, diffusion has been implemented into reactive

61 transport models based on Fick's law and diffusion coefficients are often treated as adjustable

62 parameters (Cussler, 1997). However, the number of reactive transport models that include

63 electromigration and consider the chemical potential gradient as the driving force of diffusion

64 has been growing in recent years (Parkhurst and Appelo, 1999; Giambalvo et al., 2002; Shiba et

65 al., 2005; Johannesson et al 2007; Paz-Garcia et al., 2011; Muniruzzaman et al., 2014). Although

66 some aspects of electromigration on solute transport have been investigated (Oelkers, 1996;

67 Giambalvo et al., 2002; Steefel and Maher, 2009), a direct model inter-comparison that 
68 specifically focuses on the role of electromigration and electrostatic effects on ion transport has

69 not been published to date.

70 This contribution was motivated by the need for benchmark problems suited to evaluate

71 the effect of electric coupling during multicomponent diffusion and electrochemical migration

72 and to facilitate an inter-comparison of existing reactive transport codes. The following

73 benchmark problems are specifically designed to highlight effects of electromigration. The first

74 two benchmarks are one-dimensional and the third benchmark includes two parts, involving one-

75 and two-dimensional scenarios. Three reactive transport codes were used independently for the

76 inter-comparison, namely CrunchFlow (Steefel et al., 2014), MIN3P (Mayer et al., 2002) and

77 PHREEQC (Parkhurst and Appelo, 1999).

\section{2. Governing Equations}

\section{Mass Transfer in Electrolytic Systems}

80 Species-specific diffusion is necessary to describe the behavior of electrolyte systems (Steefel

81 and Maher, 2009) where diffusive transport is the dominant mass transport process. The most

82 important feature that distinguishes the electrolyte systems from non-electrolyte systems is the

83 electric coupling of the ionic fluxes (Helfferich, 1962; Newman, 1973). In the electrolyte

84 systems, electric interaction of ion-ion, ion-solvent and ion-interface induces an electric field.

85 The treatment of electrolytic diffusion follows naturally from the generalized treatment of 86 diffusion (Taylor and Krishna, 1993).

\section{Nernst-Planck Equation for Multicomponent Systems}

88 The migration of interacting species is described by the Nernst-Planck equation, which can be 89 derived from expressions for the diffusive flux written in terms of the chemical potential (Steefel 
90 et al, 2014). Written in terms of the flux of an arbitrary species $i$, the Nernst-Planck equation is

91 given by:

92

$$
\mathbf{J}_{\mathrm{i}}=-\mathrm{D}_{\mathrm{i}}\left(\nabla \mathrm{c}_{\mathrm{i}}+\mathrm{c}_{\mathrm{i}} \nabla \ln \gamma_{\mathrm{i}}+\frac{\mathrm{c}_{\mathrm{i}} \mathrm{F}}{\mathrm{RT}} \mathrm{z}_{\mathrm{i}} \nabla \psi\right)
$$

93 where $D_{i}$ is the species-dependent diffusion coefficient $\left(\mathrm{m}^{2} \mathrm{~s}^{-1}\right), \mathrm{c}_{\mathrm{i}}$ is the concentration $\left(\mathrm{mol} \mathrm{L}^{-1}\right.$ $\left.94 \mathrm{H}_{2} \mathrm{O}\right), \gamma_{\mathrm{i}}$ is the activity coefficient (-), $\mathrm{F}$ is the Faraday constant $\left(96485 \mathrm{C} \mathrm{mol}^{-1}\right), \mathrm{R}$ is the gas 95 constant $\left(8.341 \mathrm{~J} \mathrm{~K}^{-1} \mathrm{~mol}^{-1}\right)$, $\mathrm{T}$ is the absolute temperature $(\mathrm{K}), \mathrm{z}_{\mathrm{i}}$ is the charge number $(-)$ and $\psi$ 96 is the electric potential ( $\mathrm{V}$ or $\mathrm{J} \mathrm{C}^{-1}$ ). In the presence of advection with a Darcy's velocity $\mathbf{q}$ ( $\mathrm{m} \mathrm{s}^{-}$ $97^{1}$ ), the modified flux term is:

$$
\mathbf{J}_{\mathrm{i}}=-\mathrm{D}_{\mathrm{i}}\left(\nabla \mathrm{c}_{\mathrm{i}}+\mathrm{c}_{\mathrm{i}} \nabla \ln \gamma_{\mathrm{i}}+\frac{\mathrm{c}_{\mathrm{i}} \mathrm{F}}{\mathrm{RT}} \mathrm{z}_{\mathrm{i}} \nabla \psi\right)+\mathrm{c}_{\mathrm{i}} \mathbf{q}
$$

99 This expression is known as the extended Nernst-Planck equation and holds, in ideal systems, for 100 all mobile species. It describes the movement of ions in a solution with or without external 101 electric field (Helfferich, 1962, Bard, 1980 and Bagotsky, 2006). In a multicomponent system, 102 the set of Nernst-Planck equations, one for each species, must be solved simultaneously.

103 By assuming small gradients in ionic strength, a dilute solution with low ionic strength 104 and isothermal conditions, the contribution of the flux from the gradients in the logarithms of the 105 activity coefficients can be neglected (Giambalvo et al., 2002; Steefel and Maher, 2009). With 106 this approximation, the flux of an individual species becomes:

$$
\mathbf{J}_{\mathrm{i}}=-\mathrm{D}_{\mathrm{i}}\left(\nabla \mathrm{c}_{\mathrm{i}}+\frac{\mathrm{c}_{\mathrm{i}} \mathrm{F}}{\mathrm{RT}} \mathrm{z}_{\mathrm{i}} \nabla \psi\right)+\mathrm{c}_{\mathrm{i}} \mathbf{q}
$$

108 This equation represents the contributions of diffusion, electromigration and advection to the 109 total mass transfer. Assuming there is no externally induced current (null current assumption), a 110 simplified version of the mass flux can be derived (Giambalvo et al., 2002): 


$$
\mathbf{J}_{\mathrm{i}}=-\mathrm{D}_{\mathrm{i}}\left(\nabla \mathrm{c}_{\mathrm{i}}+\mathrm{c}_{\mathrm{i}} \mathrm{z}_{\mathrm{i}} \frac{\mathbf{q} \sum_{\mathrm{j}}^{\mathrm{N}_{\text {aq }}} \mathrm{z}_{\mathrm{j}} \mathrm{c}_{\mathrm{j}}-\sum_{\mathrm{k}}^{\mathrm{N}_{\text {aq }}} \mathrm{D}_{\mathrm{k}} \mathrm{z}_{\mathrm{k}} \nabla \mathrm{c}_{\mathrm{k}}}{\sum_{\mathrm{l}}^{\mathrm{N}_{\text {aq }}} \mathrm{D}_{\mathrm{l}} \mathrm{z}_{1}^{2} \mathrm{c}_{\mathrm{l}}}\right)+\mathrm{c}_{\mathrm{i}} \mathbf{q}
$$

112 This formulation has the advantage that the electric potential does not appear as a primary

113 unknown and is therefore well suited for implementation in standard reactive transport codes.

\section{$114 \quad 3 . \quad$ Participating Codes}

115 The three reactive transport codes participating in this benchmarking exercise are CrunchFlow

116 (Steefel et al., 2014), MIN3P (Mayer et al., 2002) and PHREEQC (Parkhurst and Appelo, 1999).

117 CrunchFlow and MIN3P are 3D block-centered finite difference (finite volume) models using

118 the global implicit approach (GIA) to solve the fully coupled transport and reaction equations.

119 PHREEQC solves the multicomponent diffusion problem with a 1D finite difference method 120 using the sequential non-iterative approach (SNIA). A detailed description of the formulation 121 and capabilities of the codes is discussed elsewhere (Steefel et al., 2014 and references therein).

122 PHREEQC considers the gradients of the activity coefficients in its implementation (Appelo and

123 Wersin, 2007) whereas CrunchFlow and MIN3P neglect this contribution.

\section{$124 \quad$ 4. Benchmark Descriptions}

125 The three benchmark problems are summarized in Table 1. The first benchmark (Benchmark 1)

126 focuses on the role of electromigration in driving the flux of the various charged species to 127 maintain local charge balance and was first presented by Lichtner (1995). This problem 128 considers diffusion of $\mathrm{HNO}_{3}$ from a low $\mathrm{pH}$ solution $(\mathrm{pH}=4)$ into a circum-neutral reservoir $(\mathrm{pH}$ 129 = 6) with low $\mathrm{HNO}_{3}$ concentrations, both with the same elevated $\mathrm{NaCl}$ background 130 concentrations. 
132 Table 1. Summary of multicomponent diffusion benchmarks

\begin{tabular}{|l|l|l|c|}
\hline Benchmark & Description & Processes & Dimension \\
\hline 1 & $\begin{array}{l}\mathrm{HNO}_{3}(\mathrm{pH} \text { 4) diffusion into a } \\
\text { circum-neutral pH reservoir }\end{array}$ & Diffusion/Electromigration & 1D \\
\hline 2 & $\begin{array}{l}\text { Sodium isotope fractionation } \\
\text { induced by sodium chloride } \\
\text { diffusion in neutral pH water }\end{array}$ & Diffusion/Electromigration & $1 \mathrm{D}$ \\
\hline 3 & $\begin{array}{l}\text { Transverse dispersion affected } \\
\text { by electromigration }\end{array}$ & $\begin{array}{l}\text { Advection/Diffusion/ } \\
\text { Electromigration }\end{array}$ & 1D/2D \\
\hline
\end{tabular}

134 The second benchmark (2) shows the electromigration and subsequent fractionation of the 135 sodium isotope ${ }^{22} \mathrm{Na}^{+}$due to diffusion of $\mathrm{NaCl}$ under neutral $\mathrm{pH}$ conditions. The problem is

136 loosely based on Glaus et al (2013); however, the benchmark case presented here is set up for a

137 uniform relatively coarse-grained uncharged porous medium and does not include diffusion

138 through charged micropores as would be the case if porous clay were considered. In the first two

139 benchmarks, diffusion and electromigration are the only transport processes and models are set

140 up in one dimension. The third benchmark (3) investigates the effect of electromigration on

141 transverse dispersion and is based on experiments and modeling carried out by Rolle et al.

142 (2013). This benchmark also includes advection and is characterized by a higher level of 143 complexity; it is simulated in one- and two-dimensions.

\section{Benchmark 1: Transient Electromigration}

145 This problem was initially presented by Lichtner (1995) and has previously been used as an 146 example to illustrate the multicomponent capabilities of PHREEQC (Appelo, 2007). It is a 1D 147 transient problem with a fixed concentration (Dirichlet) boundary condition on the left $($ at $\mathrm{x}=0)$, 
representing the reservoir, and a no-flux (Neumann) boundary condition on the right $(\mathrm{x}=0.01$

$149 \mathrm{~m})$. The chemical system is composed of four primary (component) species $\left(\mathrm{H}^{+}, \mathrm{NO}_{3}{ }^{-}, \mathrm{Na}^{+}\right.$and

$\left.150 \mathrm{Cl}^{-}\right)$and one secondary species $\left(\mathrm{OH}^{-}\right)$. The porosity is set to 1.0 and the domain is discretized

151 into 100 equally spaced cells of 100 microns each. The temperature is $25^{\circ} \mathrm{C}$ and there is no flow,

152 the only transport process is multicomponent diffusion according to the Nernst-Planck equation.

153 Activity coefficients are calculated with the extended Debye-Hückel equation. Species-

154 dependent diffusion coefficients, as well as the initial and boundary conditions defining the

155 chemical system are given in Table 2.

Table 2. Boundary conditions, initial conditions, and species dependent diffusion coefficients for

158 Benchmark 1 (transient electromigration problem).

\begin{tabular}{|l|c|c|c|}
\hline Species & $\begin{array}{c}\text { Boundary Condition } \\
(\mathbf{m M})\end{array}$ & $\begin{array}{c}\text { Initial Condition } \\
(\mathbf{m M})\end{array}$ & Diffusion Coefficient $\left.\mathbf{( m}^{\mathbf{2}} \mathbf{s}^{\mathbf{- 1}}\right)$ \\
\hline $\mathrm{pH}$ & 6.001 & 4.007 & $9.31 \times 10^{-9}$ \\
\hline $\mathrm{Na}^{+}$ & 0.1 & 0.1 & $1.33 \times 10^{-9}$ \\
\hline $\mathrm{Cl}^{-}$ & 0.1 & 0.1 & $2.03 \times 10^{-9}$ \\
\hline $\mathrm{NO}_{3}{ }^{-}$ & 0.001 & 0.1 & $1.90 \times 10^{-9}$ \\
\hline $\mathrm{OH}^{-}$ & ${ }^{\mathrm{a}} 1.03 \times 10^{-5}$ & ${ }^{\mathrm{a}} 1.06 \times 10^{-7}$ & $5.27 \times 10^{-9}$ \\
\hline
\end{tabular}

${ }^{a} \mathrm{OH}$ - concentrations are only provided for completeness, calculated from $\mathrm{H}^{+}$and $\mathrm{H}_{2} \mathrm{O}\left(\mathrm{K}_{\mathrm{w}}=10^{-14}\right)$

161 The problem is run for 1 hour using a constant time step of 0.001 hour (corresponding to 1,000

162 time steps). Results are compared along the spatial profile after $\mathrm{T}=1$ hour for $\mathrm{H}^{+}, \mathrm{Na}^{+}, \mathrm{NO}_{3}{ }^{-}$and

$163 \mathrm{Cl}^{-}$.

\section{Benchmark 2: Tracer Isotope Diffusion}

165 This 1D problem involves three primary (component) species, $\mathrm{Na}^{+}, \mathrm{Cl}^{-}$, and $\mathrm{H}^{+}$, along with an 166 isotope of $\mathrm{Na}$ that is also treated as a distinct component, ${ }^{22} \mathrm{Na}^{+}$. In addition, a single secondary

167 species, $\mathrm{OH}^{-}$, is considered. In this case, fixed concentration (Dirichlet) boundary conditions are 168 considered at either end of the domain. The initial condition in the domain is divided into two 
169 regions; concentrations in half of the domain are equivalent to those at the left boundary, while

170 concentrations in the other domain half are defined by the right boundary condition. However,

171 the initial conditions are not significant since the simulation is run until steady state conditions

172 are achieved. The porosity is set to a constant and uniform value of 0.5 and the domain is

173 discretized into 100 equally spaced cells of 100 microns each. The diffusion coefficients of $\mathrm{Na}^{+}$

174 and ${ }^{22} \mathrm{Na}^{+}$are assumed to be identical. A constant time step of 1 hour is used and the simulation

175 is run to 1,500 days to ensure that steady-state is achieved. Concentrations at the boundaries and

176 species-dependent diffusion coefficients are described in Table 3. The simulation also assumes

177 no flow.

178

179 Table 3. Boundary conditions and diffusion coefficients for Benchmark 2 (isotope tracer problem).

\begin{tabular}{|l|c|c|c|}
\hline Species & $\begin{array}{c}\text { Left Boundary } \\
\text { Condition }(\mathbf{m M})\end{array}$ & $\begin{array}{c}\text { Right Boundary } \\
\text { Condition }(\mathbf{m M})\end{array}$ & Diffusion Coefficient $\left(\mathbf{m}^{2} \mathbf{s}^{-1}\right)$ \\
\hline $\mathrm{pH}$ & 7.0 & 7.0 & $9.31 \times 10^{-9}$ \\
\hline $\mathrm{Na}^{+}$ & 0.5 & 0.1 & $1.33 \times 10^{-9}$ \\
\hline${ }^{22} \mathrm{Na}^{+}$ & $10^{-6}$ & $10^{-6}$ & $1.33 \times 10^{-9}$ \\
\hline $\mathrm{Cl}^{-}$ & 0.5 & 0.1 & $2.03 \times 10^{-9}$ \\
\hline $\mathrm{OH}^{-}$ & ${ }^{\mathrm{a}} 1.05 \times 10^{-4}$ & ${ }^{\mathrm{a}} 1.03 \times 10^{-4}$ & $5.27 \times 10^{-9}$ \\
\hline
\end{tabular}

180

${ }^{\mathrm{a}} \mathrm{OH}$ - concentrations are only provided for completeness, calculated from $\mathrm{H}^{+}$and $\mathrm{H}_{2} \mathrm{O}\left(\mathrm{K}_{\mathrm{w}}=10^{-14}\right)$

182 Benchmark 3: Transverse Dispersion

183 Rolle et al. (2013) investigate the effect of electromigration on transverse dispersion under

184 steady state flow conditions. In the full 2D case, the problem involves unidirectional flow and 185 transport of a multicomponent tracer plume down the length of a 2D flow-through chamber. 


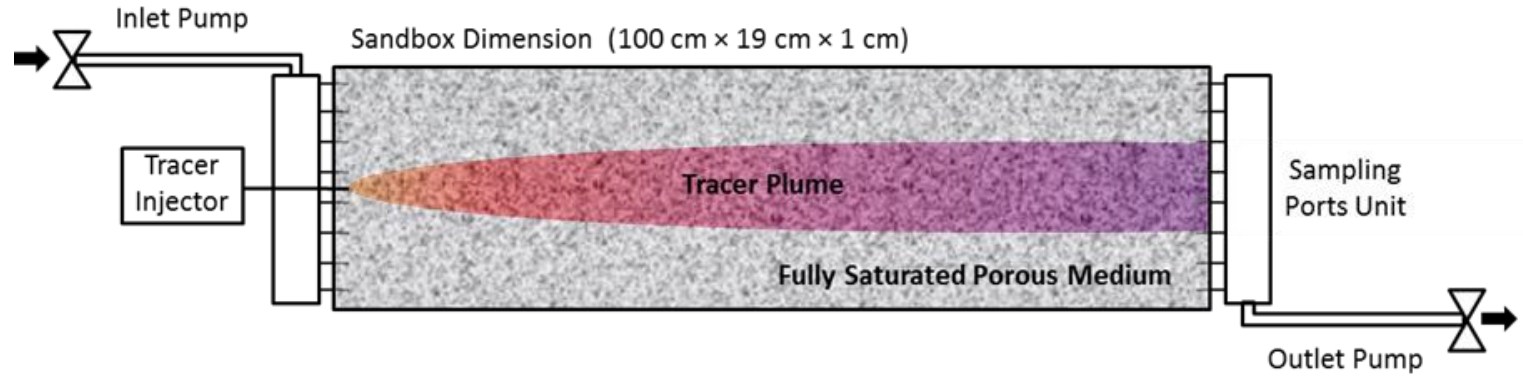

Figure 1. Schematic of the 2D flow and transverse disperison experiment conducted by Rolle et al. (2013).

Using PHREEQC, Rolle et al. (2013) solved the problem numerically by simulating transverse dispersion and electromigration perpendicular to the flow path as a 1D problem. This approach simplifies a 2D steady-state problem into a 1D transient problem by making use of the transformation $\mathrm{t}=\mathrm{x} / \mathrm{v}$, where $\mathrm{x}$ is the distance from the source for the $2 \mathrm{D}$ problem, $\mathrm{v}$ is the uniform average linear groundwater velocity, and $t$ defines the travel time to reach the location $\mathrm{x}$. At the same time, $t$ defines the simulation time for the 1D transient transverse dispersion problem (Rolle et al., 2013). Coinciding with experimental conditions, a $1 \mathrm{~cm}$ source in the middle of the $12 \mathrm{~cm}$ wide cross section at $\mathrm{x}=0$ describes the continuous release of the electrolyte solution. The simulation was run for the case of an average linear velocity of $1.5 \mathrm{~m} \mathrm{day}^{-1}$. The results of the 1D transient simulations are compared among the three participating codes, whereas fully 2D simulations with explicit treatment of flow were performed with CrunchFlow and MIN3P.

Table 4. Chemical conditions and transverse dispersion coefficients for Benchmark 3 (transverse dispersion problem).

\begin{tabular}{|l|c|c|c|c|}
\hline Species & $\begin{array}{c}\text { Tracer } \\
\text { Injection } \\
\text { Ports (mM) }\end{array}$ & $\begin{array}{c}\text { Initial Condition (1D) } \\
\text { and Remaining Injection } \\
\text { Ports (2D) }(\mathbf{m M})\end{array}$ & $\begin{array}{c}\text { Diffusion } \\
\text { Coefficient } \\
\left(\mathbf{m}^{\mathbf{2}} \mathbf{~ s}^{\mathbf{- 1}}\right)\end{array}$ & $\begin{array}{c}\text { Transverse } \\
\text { Dispersion } \\
\left.\text { Coefficient } \mathbf{( m}^{\mathbf{2}} \mathbf{~ s}^{\mathbf{- 1}}\right)\end{array}$ \\
\hline $\mathrm{K}^{+}$ & 0.29 & $10^{-6}$ & $1.77 \times 10^{-9}$ & $2.405 \times 10^{-9}$ \\
\hline $\mathrm{Mg}^{2+}$ & 0.29 & $10^{-6}$ & $6.26 \times 10^{-10}$ & $1.745 \times 10^{-9}$ \\
\hline $\mathrm{Cl}^{-}$ & 0.87 & $3 \times 10^{-6}$ & $1.81 \times 10^{-9}$ & $2.425 \times 10^{-9}$ \\
\hline
\end{tabular}


206 The dispersion coefficients used in these simulations require some discussion. In fact, the 207 parameterization of the hydrodynamic transverse dispersion coefficient used in Rolle et al. 208 (2013) differs from the classical linear model commonly adopted in subsurface applications of 209 solute transport and reads as:

$210 \quad D_{i}^{T}=D_{i}^{P}+D_{i}^{a q}\left(\frac{P e^{2}}{P e+2+4 \delta^{2}}\right)^{\beta}$

211 where $D_{i}^{P}$ is the pore diffusion coefficient approximated as the product of the aqueous diffusion 212 coefficient of a species $i$ and the porosity of the medium (0.41). $P e=v d / D_{i}^{a q}$ is the grain Péclet 213 number where $d$ is the average grain size $(1.25 \mathrm{~mm}) . \delta=6.2$, and $\beta=0.47$ are empirical parameters 214 determined in previous multitracer experiments and pore-scale simulations (Rolle et al., 2012). 215 Equation 7 explicitly retains a direct dependence of the mechanical dispersion term on the 216 aqueous diffusivity of the transported species; the non-linear dependence on the average flow 217 velocity arises from the incomplete mixing in the pore channels (e.g. Hochstetler et al., 2013; 218 Rolle and Kitanidis, 2014).

219 For this benchmark analysis we considered the mixed electrolyte case described in Rolle et al., 220 2013, where a dilute solution of $\mathrm{KCl}$ and $\mathrm{MgCl}_{2}$ was continuously injected in ambient deionized 221 water. The free aqueous diffusion coefficients of the ions at $\mathrm{T}=20^{\circ} \mathrm{C}$ are $D_{K+}=1.77 \times 10^{-9} \mathrm{~m}^{2} \mathrm{~s}^{-}$ $222{ }^{1}, D_{M g 2+}=6.26 \times 10^{-10} \mathrm{~m}^{2} \mathrm{~s}^{-1}$, and $D_{C l-}=1.81 \times 10^{-9} \mathrm{~m}^{2} \mathrm{~s}^{-1}$. These values used in Eq. 7 yield the 223 transverse dispersion coefficients given in the last column of Table 4.

224 1D Benchmark: The 1D benchmark consists of a pure transverse diffusion problem discretized 225 into 48 grid cells of $2.5 \mathrm{~mm}$. In the 1D system, the injection ports constitute initial conditions 226 used at grid cells $23-26$, corresponding to a $10 \mathrm{~mm}$ wide region in the center of the symmetrical 
227 system. The initial condition is used everywhere else in the domain and is intended to represent 228 deionized water. The transverse dispersion coefficients given in Table 4 are used. The 229 boundaries at either end of the system are treated as no-flux, but they do not influence the system 230 behavior for the 16 hour simulation time (corresponding to $\mathrm{x}=1 \mathrm{~m}$, i.e. the outflow boundary of 231 the domain). The simulation was run with a constant 0.001 hour time step.

232 2D Benchmark: For the full 2D problem solved with CrunchFlow and MIN3P, the transverse 233 discretization is 50 grid cells with a spacing of $2.4 \mathrm{~mm}$ (corresponding to a total width of 0.12 $234 \mathrm{~m})$. At the inlet boundary, grid cells $24,25,26$ and 27 in the transverse direction are set at the 235 tracer injection port concentrations of $0.29 \mathrm{mM} \mathrm{K}^{+}, 0.29 \mathrm{mM} \mathrm{Mg}^{2+}$, and $0.87 \mathrm{mM} \mathrm{Cl}^{-}$(see

236 Table 4), while the remaining injection ports carry deionized water. The longitudinal 237 discretization is 500 grid cells with a spacing of $2.4 \mathrm{~mm}$ thus a total length of $1.2 \mathrm{~m}$; the 238 concentrations are reported at $\mathrm{x}=1.0 \mathrm{~m}$, corresponding to the outflow boundary of the 239 experimental setup. The additional length of $0.2 \mathrm{~m}$ is considered in the models to avoid any 240 possible boundary effects. In this case, lateral flow can be calculated, or simply prescribed at 1.5

$241 \mathrm{~m}$ day $^{-1}$. A maximum time step of 1 hour is used with an initial minimum time step of $10^{-6}$ hours.

242 The simulation time is 32 hours to ensure that the final results correspond to steady state 243 conditions representative of the experiment.

\section{$244 \quad$ 5. Results and Discussion}

\section{Benchmark 1}

246 Simulation results for the Benchmark 1 (Lichtner, 1995) depict the diffusion of $\mathrm{HNO}_{3}(\mathrm{pH}=$ 247 4.007) from the solution domain towards the boundary where $\mathrm{NO}_{3}{ }^{-}$concentration are 100 times 248 lower and $\mathrm{pH}=6.001$. Results for $\mathrm{NO}_{3}{ }^{-}$and $\mathrm{H}^{+}$reveal that both ions continue to diffuse towards 
249 the left boundary after 1 hour simulation time (Figure 2). Because the diffusion coefficient for

$250 \mathrm{H}^{+}$is much larger than the corresponding value for $\mathrm{NO}_{3}^{-}, \mathrm{H}^{+}$has become substantially more

251 depleted in the domain than $\mathrm{NO}_{3}{ }^{-}$. The discrepancy in diffusion rates of $\mathrm{H}^{+}$and $\mathrm{NO}_{3}{ }^{-}$triggered

252 electromigration of $\mathrm{Na}^{+}$and $\mathrm{Cl}^{-}$to maintain local charge balance; $\mathrm{Na}^{+}$is entering the domain to

253 offset the preferential loss of $\mathrm{H}^{+}$, while $\mathrm{Cl}^{-}$is leaving the system to counterbalance $\mathrm{NO}_{3}{ }^{-}$, which

254 is preferentially retained. Migration of $\mathrm{Na}^{+}$and $\mathrm{Cl}^{-}$occurs despite the fact that there was no

255 initial concentration gradient of either species (Table 2) and takes place even against the

256 developing concentration gradients of $\mathrm{Na}^{+}$and $\mathrm{Cl}^{-}$. If Fick's Law were used to describe this

257 multispecies diffusion problem, there would be no change in $\mathrm{Na}^{+}$and $\mathrm{Cl}^{-}$concentration and

258 consequently electroneutrality would be violated.

259 There is very good agreement between the simulation results of all three codes and they

260 demonstrate near identical outputs. Simulations were executed on a desktop computer equipped

261 with an Intel Core 2 Quad CPU with two $2.4 \mathrm{GHz}$ processors, 8 GB RAM and a 64-bit operating

262 system.

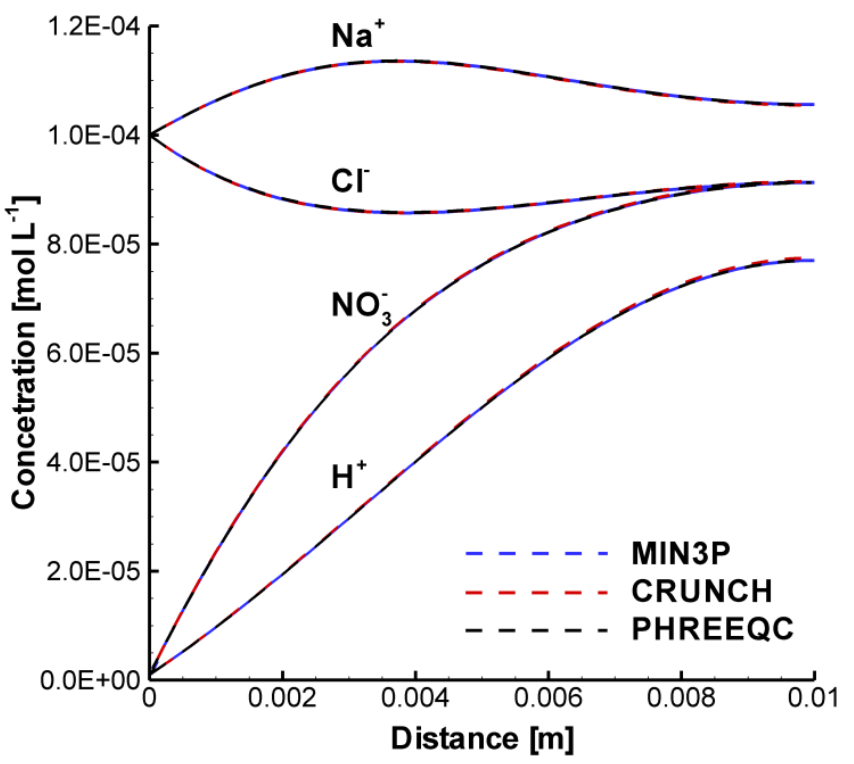


Figure 2: Species concentrations after 1 hour simulation time for $\mathrm{HNO}_{3}$ diffusion (Benchmark 1). The left boundary is a fixed concentration (Dirichlet) boundary, while the right boundary is no-flux.

Benchmark 2

269 The results of the Benchmark 2 simulation visually show steady state diffusion with same

270 concentration profiles for $\mathrm{Na}^{+}$and $\mathrm{Cl}^{-}$from left to right (

271 Figure 3). However, it has to be kept in mind that the diffusion coefficient for $\mathrm{Cl}^{-}$is considerably

272 larger than the one for $\mathrm{Na}^{+}$. In fact, considering that the equations are based on the null current 273 assumption, this holds back $\mathrm{Cl}^{-}$migration and accelerates $\mathrm{Na}^{+}$migration. Although there are no 274 initial concentration gradients for ${ }^{22} \mathrm{Na}^{+}, \mathrm{H}^{+}$and $\mathrm{OH}^{-}$, these species, present at much lower 275 concentrations, also become affected by the electrostatic coupling.
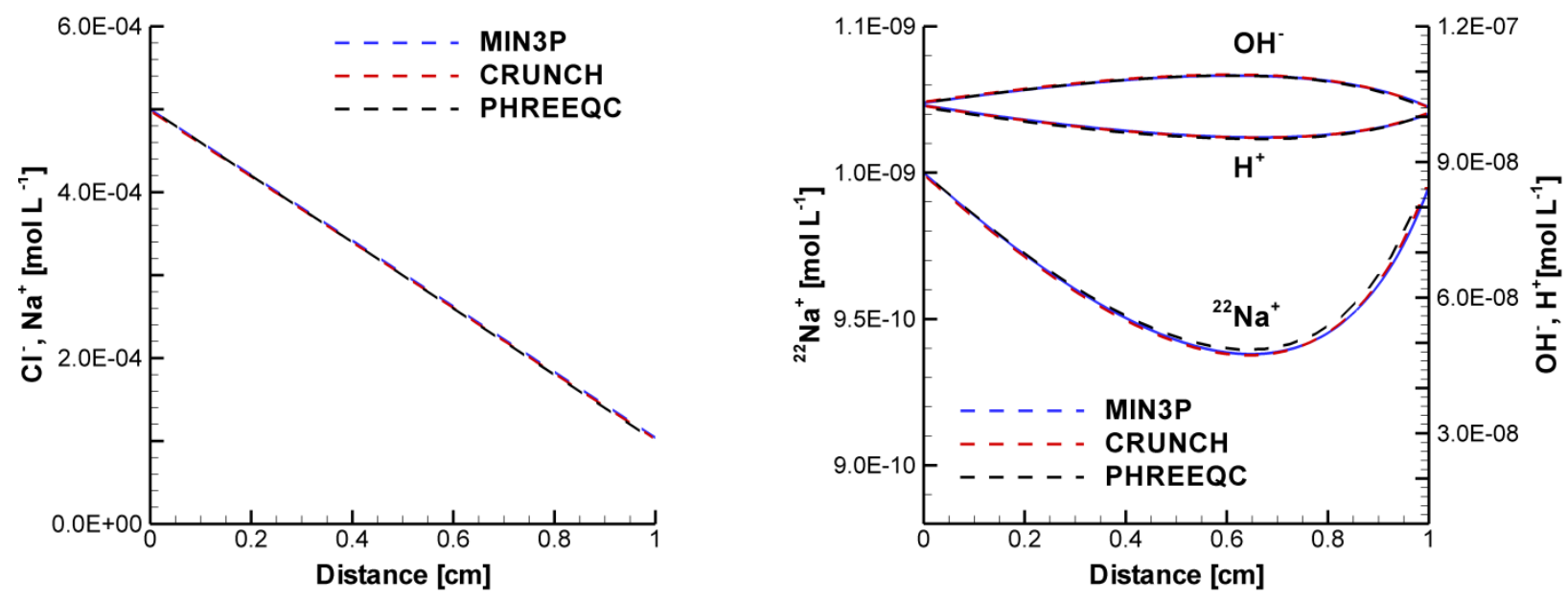

Figure 3: $\mathrm{Na}^{+}, \mathrm{Cl}^{-}, \mathrm{H}^{+}, \mathrm{OH}^{-}$and ${ }^{22} \mathrm{Na}^{+}$concentrations after 1500 days for system summarized in Table 2 (Benchmark 2). The left boundary is a fixed concentration (Dirichlet) boundary at $0.5 \mathrm{mM}$, while the right boundary is a fixed concentration boundary at $0.1 \mathrm{mM}$ for $\mathrm{Na}^{+}, \mathrm{Cl}^{-}$. The fixed gradient in $\mathrm{NaCl}$ of the column. 
285 A closer look at the results reveals that $\mathrm{H}^{+}$migrates from the left to the right to enhance the 286 positive charge flux, while $\mathrm{OH}^{-}$migrates from the right to the left to counteract the negative

287 charge flux from the left to the right dominated by $\mathrm{Cl}^{-}$. Primarily, one would expect that ${ }^{22} \mathrm{Na}^{+}$ 288 should also be subjected to a net flux from the left to the right; however, the sodium isotope is 289 present at very low concentrations and is more strongly affected by migration dynamics of $\mathrm{H}^{+}$ 290 and $\mathrm{OH}^{-}$, resulting in a net migration form the right to the left inducing an unexpected isotope 291 fractionation. Solving this problem with Fick's law would not predict ${ }^{22} \mathrm{Na}^{+}$isotope fractionation, $292 \mathrm{H}^{+}$and $\mathrm{OH}^{-}$migration, and would result in a net negative charge flux across the domain. These 293 results suggest that multicomponent diffusion can introduce isotope fractionation, even in the 294 absence of fractionating reactions.

295 Overall, there is very good agreement between the three codes with better agreement between 296 CrunchFlow and MIN3P. Slight differences are observed for the PHREEQC results. It is difficult 297 to decisively determine the reasons for these differences, but it is likely that the discrepancies are 298 due to slight variations in model formation (i.e. consideration of activity gradients in the 299 PHREEQC formulation, absent in the other two codes) and/or the use of different coupling 300 schemes (GIM vs. SNIA). However, all codes show identical trends and concentration 301 differences are small, implying that the residual discrepancies will not affect the interpretation of 302 the results.

\section{Benchmark 3: 1D Transverse Dispersion}

305 The transverse concentration profiles for $\mathrm{Cl}^{-}, \mathrm{K}^{+}$and $\mathrm{Mg}^{2+}$ are plotted at the outlet $(\mathrm{x}=1.0 \mathrm{~m})$

306 corresponding to a residence time of 16 hours in the 2D domain. The separation of the three 307 tracer profiles ( 
308 Figure 4) demonstrates the effect of species-dependent dispersion coefficients and 309 electrochemical migration on transverse displacement. The $\mathrm{Cl}^{-}$concentration profile is located

310 between $\mathrm{K}^{+}$and $\mathrm{Mg}^{2+}$ despite having the largest diffusion coefficient. In fact, $D_{C l}$ in liberated 311 state is considerably larger than $D_{M g 2+}$ and also slightly larger than $D_{K+}$ (Table 4). These results

312 show that $\mathrm{Cl}^{-}$migration is retarded due to electrostatic coupling with the cations and in particular 313 with $\mathrm{Mg}^{2+}$, which diffuses more slowly. The outcomes reported in Fig. 4 demonstrate the 314 positive contribution of electromigration to transverse displacement of the two cations and the 315 negative contribution of electromigration to transverse displacement of chloride (Rolle et al., 316 2013).

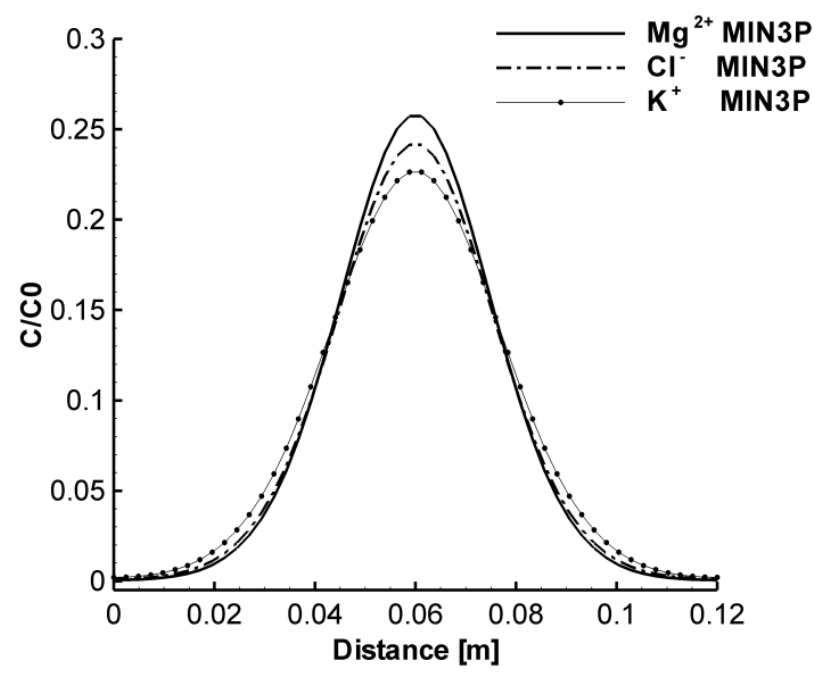

319 Figure 4. 1D simulation results of transverse profiles for $\mathrm{Cl}^{-}, \mathrm{K}^{+}$and $\mathrm{Mg}^{2+}$ at the outlet (corresponding to 320 a residence time of 16 hours) demonstrate the effect of species-dependent dispersion and electromigration 321 on the transverse displacement of charged species (1D Benchmark 3 solved with MIN3P).

323 There is a very good agreement between the three codes and an excellent match between 324 CrunchFlow and MIN3P ( 
Figure 5). Similar to the two previous benchmarks, there are slight differences between the results of CrunchFlow and MIN3P on the one hand and PHREEQC on the other hand. Peak

327 chloride concentrations predicted by PHREEQC are slightly higher than those calculated by 328 CrunchFlow and MIN3P ( 0.6\%). Magnesium and potassium concentration profiles are in very 329 good agreement for all codes.
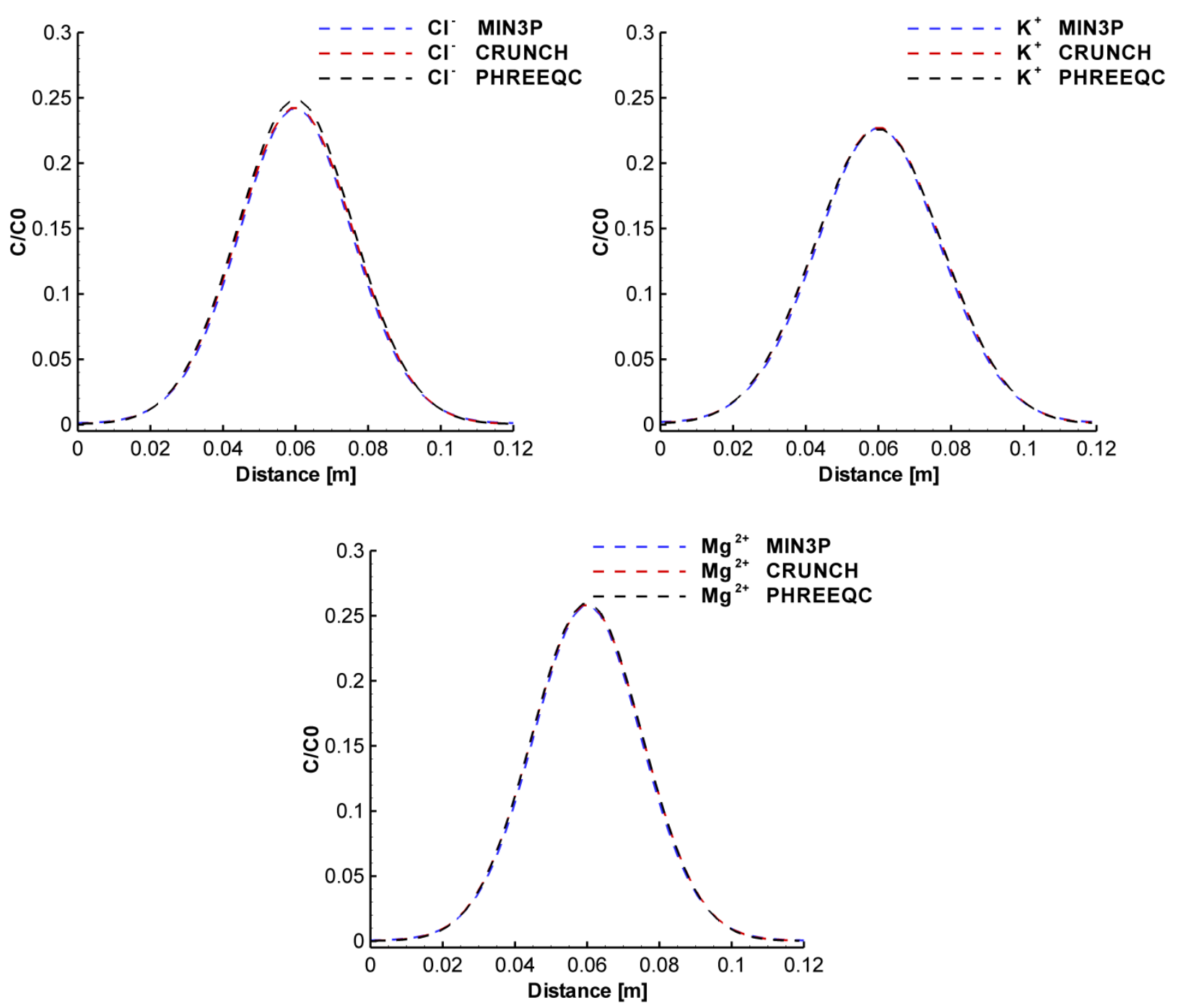

Figure 5. 1D simulation of transverse multicomponent diffusion for the case of transport of mixed electrolytes ( $\mathrm{KCl}$ and $\mathrm{MgCl}_{2}$ solution) in pure water described by Rolle et al. (2013), comparing 335 CrunchFlow, MIN3P and PHREEQC results. 


\section{Benchmark 3: 2D Flow and Transverse Dispersion}

338 Using CrunchFlow and MIN3P it was possible to carry out a full two-dimensional flow and 339 multicomponent transport simulation of the flow-through system. The simulation was run for

340 two pore volumes (32 hours) to ensure that steady state conditions at the outflow were reached.

341 To illustrate the 2D concentration distributions and to provide a means for visual comparison of

342 the CrunchFlow and MIN3P results, 2D contour plots are provided for $\mathrm{K}^{+}, \mathrm{Mg}^{2+}$ and $\mathrm{Cl}^{-}$(Figure 343 6). 

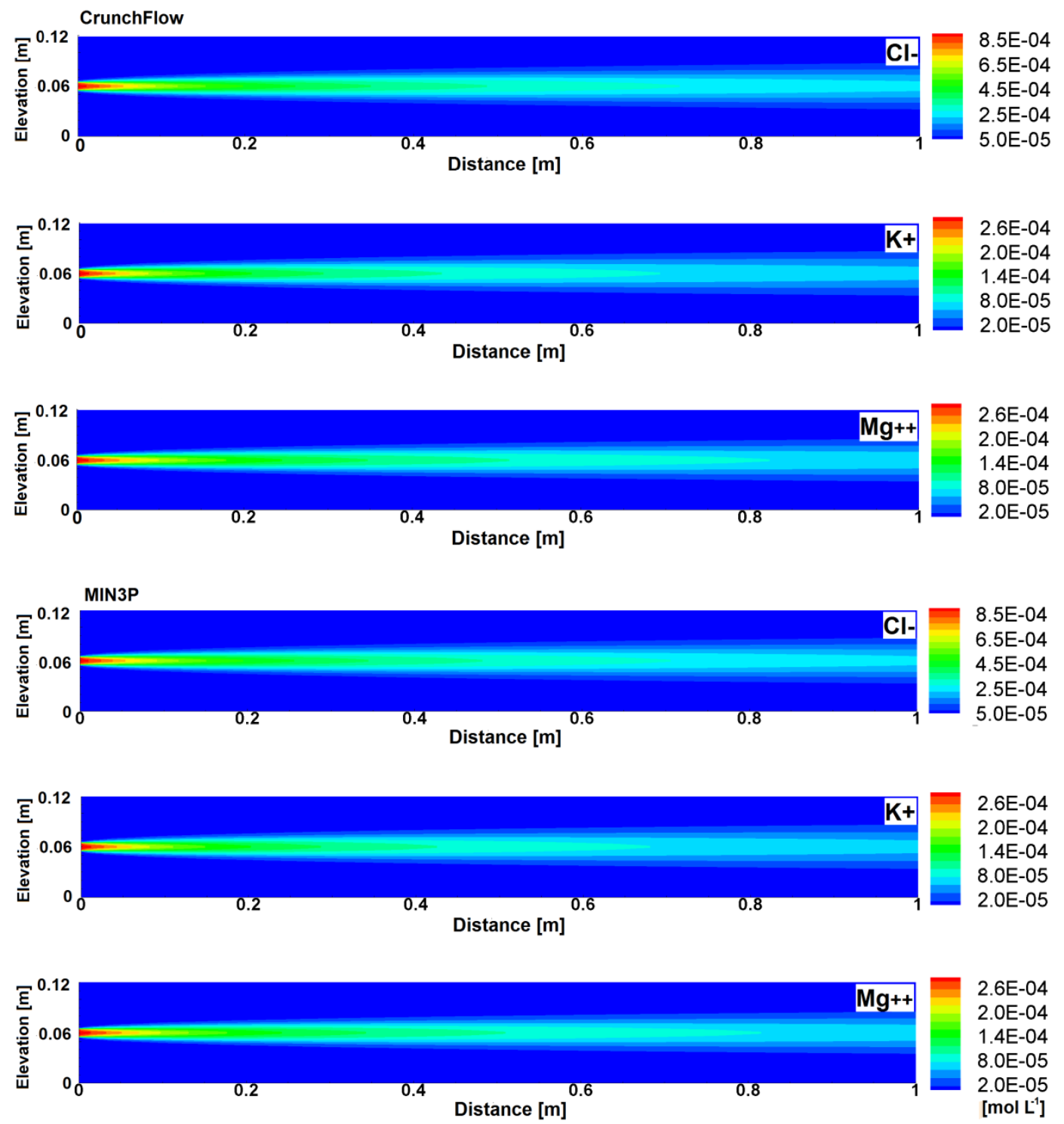
Figure 6. Simulation results for Benchmark 3 considering flow (uni-directional) and multicomponent
347 transverse dispersion for steady-state conditions, from top to bottom are shown: $\mathrm{K}^{+}, \mathrm{Mg}^{2+}$ and $\mathrm{Cl}^{-}$for 348 CrunchFlow and $\mathrm{K}^{+}, \mathrm{Mg}^{2+}$ and $\mathrm{Cl}^{-}$for MIN3P.

350 Cross-sections extracted from two-dimensional steady state CrunchFlow and MIN3P results are 351 compared at the outflow to one-dimensional transient PHREEQC results, corresponding to a 352 residence time of 16 hours. Overall, there is an excellent agreement between MIN3P and 353 CrunchFlow results (Figure 7) and results are also very close to the concentrations computed with the 354 1D PHREEQC approach. PHREEQC concentration profiles are slightly higher than CrunchFlow 
355 and MIN3P (the differences of the peak concentrations are $\sim 0.6 \%$ for $\mathrm{Cl}^{-}, \sim 0.7 \%$ for $\mathrm{Mg}^{2+}$ and $356 \sim 0.4 \%$ for $\mathrm{K}^{+}$).
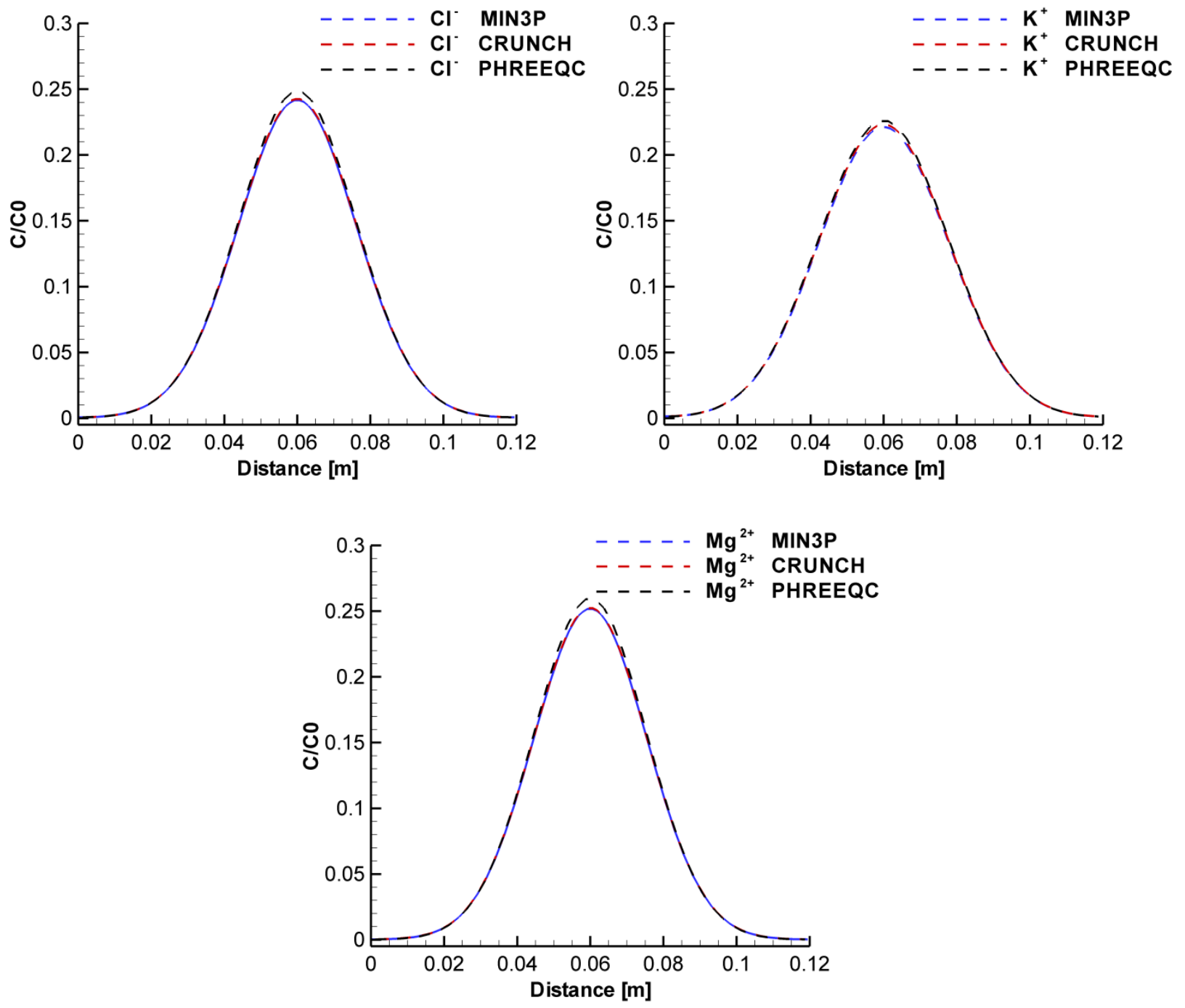

Figure 7. Comparison of 1D PHREEQC results (no explicit consideration of flow, only following the plume as it moves down the flow path) and transverse profiles derived from 2D CrunchFlow and MIN3P runs for the transverse dispersion problem. The CrunchFlow 2D runs are based on GIMRT and use a first order upwind formulation, along with a backwards Euler time stepping approach, the same numerical

363 methods are used in the MIN3P simulations. 


\section{Concluding Remarks}

366 Three benchmark problems were presented, each with significant effects of multicomponent 367 diffusion and electromigration on transport of solutes in saturated porous media. The 368 benchmarks were specifically designed to be sensitive to the effect of electromigration on 369 diffusion and lateral concentration displacement. Benchmarks 1 and 2 are hypothetical problems 370 that provide opportunities to verify the implementation of multicomponent diffusion and 371 electromigration formulations in reactive transport codes. Benchmark 3 is based on the outcomes 372 of laboratory experiments (Rolle et al., 2013) and provides the opportunity to verify and validate 373 multicomponent diffusion and species-dependent transverse dispersion formulations under flow374 through conditions. Three reactive transport codes with the capability of simulating 375 multicomponent diffusion and electrochemical migration participated in this study (CrunchFlow, 376 MIN3P and PHREEQC). For all benchmark problems considered in this work an overall very 377 good agreement between the simulation results obtained with the different codes. Despite some 378 residual discrepancies between the simulation results, all three codes were able to consistently 379 reproduce the same trends and evolution in concentration patterns induced by multicomponent 380 diffusion and by the electrostatic interactions between the charged species. Small discrepancies 381 between the results indicate that different approaches in implementing the governing equations 382 are not a significant source of uncertainties for model applications; uncertainties will rather be 383 dominated by the underlying conceptual model.

\section{Acknowledgements:}

385 Funding for this research was provided by the Natural Sciences and Engineering Research 386 Council of Canada (NSERC) in form of a Discovery Grant and a Discovery Accelerator 
387 Supplement Award held by K. Ulrich Mayer. The contribution of C. Steefel was supported by 388 the Director, Office of Science, Office of Basic Energy Sciences, Chemical Sciences, 389 Geosciences, and Biosciences Division, of the U.S. Department of Energy under Contract No. 390 DE-AC02-05CH11231. M. Rolle acknowledges the support of the Baden-Württemberg Stiftung 391 under the Eliteprogram for postdocs.

$393 \quad$ References:

394 1. Alt-Epping, P., Tournassat, C., Rasouli, P., Steefel, C., Mayer, K., Jenni, A., Mäder, U., 395 Sengor, S., Fernandez, R.: Benchmark reactive transport simulations of a column experiment 396 in compacted bentonite with multispecies diffusion and explicit treatment of electrostatic 397 effects. Comput. Geosci. (2015). doi:10.1007/s10596-014-9451-x

398 2. Appelo, C.A.J.:Multicomponent diffusion in clays. In: Candela, L., Vadillo, I., Aagaard, P. 399 (eds.) Water Pollution in Natural Porous Media, pp. 3-13. Instituto Geologico de Espana, $400 \quad$ Madrid (2007)

401 3. Appelo, C.A.J., Wersin, P.: Multicomponent diffusion modeling in clay systems with 402 application to the diffusion of tritium, iodide, and sodium in Opalinus Clay. Environ. Sci. $403 \quad$ Technol. 41, 5002-5007 (2007)

404 4. Appelo, C.A.J., Van Loon, L.R., Wersin, P.: Multicomponent diffusion of a suite of tracers 405 (HTO, Cl, Br, I, Na, Sr, Cs) in a single sample of Opalinus Clay. Geochim. Cosmochim. $406 \quad$ Acta 74, 1201-1219(2010)

407 5. Bagotsky, V.S.: Fundamentals of Elechtrochemistary, 2nd edn. John Wiley and Sons, $408 \quad$ Pennington (2006) 
409 6. Bard, A.J., Faulkner, L.R.: Electrochemical Methods: Fundamentals and Applications. $410 \quad$ John Wiley and Sons, New York (1980)

411 7. Ben-Yaakov, S.: Diffusion of seawater ions-significance and consequences of cross 412 coupling effects. Am. J. Sci. 281, 974-980 (1981)

413 8. Boudreau, B.P.: Diagenetic models and their implementation. Springer, New York (1997)

414 9. Boudreau, B.P., Meysman, F.J.R., Middelburg, J.J.: Multicomponent ionic diffusion in 415 porewaters: Coulombic effects revisited. Earth Planet. Sci. Lett. 222, 653-666 (2004)

416 10. Carrera, J., Sanchez-Vila, X., Benet, I., Medina, A., Galarza, G., Guimera, J.: On matrix 417 diffusion: formulations, solution methods and qualitative effects. Hydrogeol. J. 6, 178-190 $418 \quad(1998)$

419 11. Chiogna, G., Cirpka, O.A., Grathwohl, P., Rolle, M.: Relevance of local compound420 specific transverse dispersion for conservative and reactive mixing in heterogeneous porous 421 media.Water Resour. Res. 47, W06515 (2011). doi:10.1029/2010WR010270

422 12. Cussler, E.L.: Diffusion: Mass Transfer in Fluid Systems, 2nd edn. Cambridge University $423 \quad$ Press, New York (1997)

424 13. Giambalvo, E.R., Steefel, C.I., Fisher, A.T., Rosenberg, N.D., Wheat, C.G.: Effect of 425 fluid-sediment reaction on hydrothermal fluxes of major elements, eastern flank of the Juan 426 de Fuca Ridge. Geochim. Cosmochim. Acta 66, 1739-1757 (2002)

427 14. Glaus, M.A., Birgersson, M., Karnland, O., Van Loon, L.R.: Seeming steady-state uphill 428 diffusion of $22 \mathrm{Na}+$ in compacted montmorillonite. Environ. Sci. Tech. 47, 11522-11527 $429 \quad(2013)$

430 15. Helfferich, F.: Ion Exchange, 2nd edn. McGraw-Hill, New York (1962) 
16. Hochstetler, D.L., Rolle, M., Chiogna, G., Haberer, C.M., Grathwohl, P., Kitanidis, P.K.:

432 Effects of compound-specific transverse mixing on steady-state reactive plumes: insights

433 from porescale simulations and Darcy-scale experiments. Adv.Water Resour. 54, 1-13

434 (2013). doi:10.1016/j.advwatres.2012.12.007

435 17. Johannesson, B., Yamada, K., Nilsson, L.O., Hosokawa, Y.: Multispecies ionic diffusion

436 in concrete with account to interaction between ions in the pore solution and the cement

437 hydrates. Materials and Structures, Kluwer Academic Publishers, 40, 651-665 (2007)

438 18. Kang, Q., Lichtner, P.C., Zhang, D.: Lattice Boltzmann porescale model for multi439 component reactive transport in porous media. J. Geophys. Res 111, B05203 (2006). 440 doi:10.1029/2005JB003951

441 19. LaBolle, E.M., Fogg, G.E.: Role of molecular diffusion in contaminant migration and 442 recovery in alluvial aquifer system. Transp. Porous Media 42, 155-179 (2001)

443 20. Lasaga, A.C.: Treatment ofmulticomponent diffusion and ion-pairs in diagenetic fluxes.

444 Am. J. Sci. 279, 324-346 (1979)

445 21. Lichtner, P.C.: Principles and practice of reactive transport modeling. Mater. Res. Soc. $446 \quad$ Symp. Proc. 353, 117-130 (1995)

447 22. Lichtner, P.C.: Continuum formulation of multicomponent-multiphase reactive transport.

448 Ch. 1 in. reactive transport in porous media. In: Lichtner, P.C., Steefel, C.I., Oelkers, E.H. 449 (eds.) Reviews in Mineralogy, vol. 34. Mineralogical Society of America, Washington, DC $450 \quad(1996)$

451 23. Liu, C.X., Shang, J., Zachara, J.M.: Multispecies diffusion models: a study of uranyl 452 species diffusion.Water Resour. Res. 47, W12514 (2011). doi:10.1029/2011WR010575 
24. MacQuarrie, K.T.B., Mayer, K.U.: Reactive transport modeling in fractured rock: a state-

454 of-the-science review. Earth Sci. Rev. 72, 189-227 (2005)

455 25. Mayer, K.U., Frind, E.O., Blowes, D.W.: A numericalmodel for the investigation of 456 reactive transport in variably saturated media using a generalized formulation for kinetically 457 controlled reactions.Water Resour. Res. 38, 1301-1321 (2002). doi:10:1029/2001WR000862

458 26. McDuff, E.R., Ellis, A.R.: Determining diffusion-coefficients in marine-sediments459 laboratory study of the validity of resistivity techniques. Am. J. Sci. 279, 666-675 (1979)

460 27. Molins, S., Trebotich, D., Steefel, C.I., Shen, C.: An investigation of the effect of pore $461 \quad$ scale flow on average geochemical reaction rates using direct numerical simulation. Water 462 Resour. Res. 48, W03527 (2012). doi: 10.1029/2011WR011404

463 28. Muniruzzaman, M., Haberer, C.M., Grathwohl, P., Rolle, M.: Multicomponent ionic 464 dispersion during transport of electrolytes in heterogeneous porous media: experiments and 465 model-based interpretation. Geochim. Cosmochim. Acta 141, 656-669 (2014)

466 29. Newman, J.S.: Electrochemical Systems. Prentice-Hall, Englewood Cliff (1973)

467 30. Oelkers, E.H.: Physical and chemical properties of rocks and fluids for chemical mass 468 transport calculations. Rev. Mineral. Geochem. 34, 131-191 (1996)

469 31. Ovaysi, S., Piri, M.: Pore-scale dissolution of CO2+SO2 in deep saline aquifers. Int. J. $470 \quad$ Greenh. Gas Control 15, 119-133 (2013)

471 32. Parkhurst, D.L., Appelo, C.A.J.: User's guide to PHREEQC (version 2)—a computer 472 program for speciation, batch-reaction, onedimensional transport, and inverse geochemical $473 \quad$ calculations. Denver (1999) 
474 33. Paz-Garcia, J.M., Johannesson, B., Ottosen, L.M., Ribeiro, A.B.., Rodriguez-Maroto,

475 J.M.: Modeling of electrokinetic processes by finite element integration of the Nernst476 Planck-Poisson system of equations. Sep. Purif. Technol. 79, 183-192 (2011)

477 34. Rolle, M., Hochstetler, D.L., Chiogna, G., Kitanidis, P., Grathwohl, P.: Experimental 478 investigation and pore-scale modeling interpretation of compound-specific transverse 479 dispersion in porous media. Transp. Porous Media 93, 347-362 (2012)

480 35. Rolle, M., Muniruzzaman, M., Haberer, C.M., Grathwohl, P.: Coulombic effects in 481 advection-dominated transport of electrolytes in porous media: multicomponent ionic 482 dispersion. Geochim. Cosmochim. Acta 120, 195-205 (2013)

483 36. Rolle, M., Chiogna, G., Hochstetler, D.L., Kitanidis, P.K.: On the importance of diffusion 484 and compound-specific mixing for groundwater transport: an investigation from pore to field 485 scale. J. Contam. Hydrol. 153, 51-68 (2013)

486 37. Rolle,M., Kitanidis, P.K.: Effects of compound-specific dilution on transient transport 487 and solute breakthrough: a pore-scale analysis. Adv. Water Resour. 71, 186-199 (2014)

488 38. Shiba, S., Hirata, Y., Seno, T.: Mathematical model for hydraulically aided electrokinetic 489 remediation of aquifer and removal of nonanionic copper. Eng. Geol. 77, 305-315 (2005)

490 39. Steefel, C.I., Carroll, S.A., Zhao, P., Roberts, S.: Cesium migration in Hanford sediment: 491 a multisite cation exchange model based on laboratory transport experiments. J. Contam. $492 \quad$ Hydrol. 67, 219-246 (2003)

493 40. Steefel, C.I., Maher, K.: Fluid-rock interaction: a reactive transport approach. Rev. 494 Mineral. Geochem. 70, 485-532 D2009]. Mineralogical Society of America 
495 41. Steefel, C.I., Appelo, C.A.J., Arora, B., Jacques, D., Kalbacher, T., Kolditz, O., Lagneau, 496 V., Lichtner, P.C., Mayer, K.U., Meeussen, J.C.L.,Molins, S.,Moulton, D., Shao, H., 497 Šimůnek, J., Spycher, N., Yabusaki, S.B., Yeh, G.T.: Reactive transport codes for subsurface 498 environmental simulation. Comput. Geosci. (2014). doi:10.1007/s10596-014-9443-x

499 42. Taylor, R., Krishna, R.: Multicomponent Mass Transfer. John Wiley and Sons, New $500 \quad$ York (1993)

501 43. Tyrrell, H.J.V.: Diffusion and Heat Flow in Liquids. Butterworths, London (1961)

502 44. Van Cappellen, P., Gaillard, J.F.: Biogeochemical dynamics in aquatic sediments. Ch. 8 503 in.: reactive transport in porous media. In: Lichtner, P.C., Steefel, C.I., Oelkers, E.H. (eds.) 504 Reviews in Mineralogy, vol. 34, pp. 335-376. Mineralogical Society of America, $505 \quad$ Washington, DC (1996)

506 45. Vinograd, J.R., McBain, J.W.: Diffusion of electrolytes and of the ions in their mixtures. $507 \quad$ J. Am. Chem. Soc. 63, 2008-2015 (1941)

508 46. Wang, Y., Van Cappellen, P.: A multicomponent reactive transport model of early 509 digenesis: application to redox cycling in coastal marine sediments. Geochim. Cosmochim. $510 \quad$ Acta 60, 2993-3014 (1996) 